\title{
Transformation of Indian Sponge Iron Industry Vis-à-vis Quality Management: A Literature Review
}

\author{
V. S. Gorantiwar $\cdot$ R. L. Shrivastava
}

Received: 8 November 2012/ Accepted: 21 April 2014/Published online: 21 May 2014

(C) The Institution of Engineers (India) 2014

\begin{abstract}
Since the last 30 years, the Indian Sponge Iron (SI) industry has grown by leaps and bounds. Though the sector has undergone rapid growth in recent past, the growth graph is not likely to be sustained due to multiple geo-political and other related factors. Besides, the opening up of the economy has given unprecedented importance to the issues pertaining to quality at all levels i.e. from raw material to the product, without forgetting the actual processing that takes place in the industrial units. In view of absence of a clear cut, valid and reliable quality management framework for the SI industry, this review was carried out to determine the research gaps and further research needs specifically for this sector. The literature review indicated that there is a dearth of literature pertaining to SI industry in general and the quality management issue in this industry in particular. Hence, there is a need to identify critical factors that govern the quality in the SI industry, specifically for the Indian industries. Furthermore, the use of mathematical models are also desired so as to improve its application on wider scale.
\end{abstract}

Keywords SI industry · Quality management . Critical success factors · Mathematical model

\footnotetext{
V. S. Gorantiwar $(\bowtie)$

Dept. of Mech. Engg, Rajiv Gandhi College of Engg. Research

\& Technology, Babupeth, Chandrapur 442 403, M.S., India

e-mail: vinodsg@hotmail.com

R. L. Shrivastava

Dept. of Mech. Engg, Yeshwantrao Chavan College of

Engineering, Wanadongari, Nagpur 441 110, India

e-mail: rlshrivastava@yahoo.com
}

\section{Introduction}

The Iron and Steel Industry has been traditionally considered as one of the most important industrial sectors, which has a large share in India's GDP and the overall development. Though the Indian Iron and Steel Industry is nearly a century old, it is still in the transformation phase, especially due to the competition offered by globalization. Today, not only the Iron and Steel Industry, but also other industries (which were in existence for over a century), are caught up in a situation where they have to change themselves significantly as well as rapidly with respect to various processes integral to them. As far as the Iron and Steel industry sector in India is concerned, it is the first core sector, which was completely freed from the licensing, pricing and distribution control in the year 1990-1991 [1]. It is well known that the economic modernization processes (mainly in India and China) are driving the steep rise in demand for steel and in turn the raw material i.e. SI.

The recent steel production data indicates that India has emerged as the fifth largest producer of steel in the world and is likely to become the second largest producer of crude steel by 2015-2016 [2]. The comparative advantage of India's Iron and Steel industry lies in the fact that the country has a ready domestic availability of significant reserves of high quality iron ore. The state of Odisha contains about 3,000 million tons of iron ore which accounts for $25 \%$ of India's Iron ore reserves [3].

Many government initiatives have been aimed at increasing investment in the steel industry in India such as

1. Allowing private ownership and foreign investment

2. Improving intellectual property laws

3. Deregulation of pricing and distribution of iron and steel 
4. Favorable changes in Custom Policy

5. Introduction of Special Economic Zones

6. Setting up of Special Investment Regions

The changes in the SI industry are expected to be speedy, especially in view of the new industrial policy adopted by the government of India, which has opened up this sector to private investment, which is expected to bring in the latest technology. While the existing units are being modernized/expanded, a large number of new plants have also come up based on modern, cost effective, state of the art technologies. However, the resources that are needed to efficiently run these modern systems, gadgets, processes often lag behind in the technologies used. To add to the woes of the industry, many problems are faced by the industry (SI Manufacturers) in varying degrees. These are

- Very high fluctuation in cost of iron ore (with high Fe content)

- Poor quality of coal that creates environmental hazards

- Poor quality of iron ore, which reduces the yield of liquid steel production and creates environmental hazards

- High ash content in coal and contamination in iron ore results in accretion and low campaign life of the kiln.

- The large quantity of fines (about 25-45\%) generated in the product during the processing, affects the profit margins.

- High cost for environmental compliance with respect to waste disposal

- High cost of power (Steel industry is power intensive and the high cost of power makes the steel production in India uncompetitive with respect to other countries in the world.)

- Non-availability of metallurgical coke, import of metallurgical coke increases the production cost of steel.

- Endemic deficiencies with respect to the quality and availability of some of the essential raw materials.

- Low labour productivity

- Other systemic deficiencies such as poor quality of basic infrastructure like road, port etc, lack of funding in $R \& D$, delay in absorption of the latest technology by existing units, non-availability of good quality of iron ore, high level of taxation etc.

The socio-economic dynamics and the human development in world have allowed a predictability as far as certain industrial areas are concerned. For example, the SI industry (which acts as a supplier to steel and iron industries) will demand higher and higher productivity from the plants. However, it has been observed that the production related technologies often advance at a much higher speed than their implementation. In view of this it is evident that there are certain gaps in the R\&D associated with many industrial sectors in general and SI industry in particular. Hence, in view of the above information, this study was carried out to determine various aspects that are critical for quality as well as productivity in the field of SI industry.

Though India has an advantage in having cheaper labour availability than that in other developing as well as developed nations, the situation may not remain so for long. The prevailing industrial scenario is likely to change faster than it was anticipated-the advent of information technology has remarkably effected changes in various domains of industrial sector and labour related aspects are no exception.

\section{Methodology}

In the backdrop of the above information, literature review was carried out to identify the past research efforts and directions related to quality and productivity management in SI industry. The objective was to identify the research gaps and highlight research motivations for addressing the critically important aspects of the quality and productivity related issues in SI industries of India. Care was taken to reproduce the original terminology used by the authors to preserve the originality of the views pertaining to the domain under investigation i.e. SI industry. Using the principles of deductive reasoning, the published literature was systematically reviewed by selecting the literature published in standard journals. Based on the review, the discussion is presented in this manuscript in distinctly different sections.

\section{Discussion}

The comprehensive study of SI industry is necessary, especially in view of its very strong forward and backward linkages in terms of material flow, income generation and employment creation. The SI industry in India is three decades old as the first demonstration SI plant of 100 TPD capacity kiln started in 1980 at Sponge Iron India Ltd, Paloncha A.P. Subsequently the industry has grown significantly and now India is the largest coal-based SI producer in the world [4]. Besides, the consumption of iron and steel is primarily driven by the manufacturing, construction and infrastructure sectors, which have witnessed impressive growth in India in past few years [5]. With the production of 26.71 million tons production of SI in the year 2010-2011, India maintained its first position from 2004 [6]. However, the year 2011-2012 has presented a dismal picture for the steel industry, as the country's industrial growth in general and that of the manufacturing sector in particular have nose-dived to lower levels [7]. The 
Table 1 Production, installed capacity and capacity utilization of gas and coal based SI

\begin{tabular}{lll}
\hline Particulars & $2009-2010$ & $2010-2011$ \\
\hline Production of gas based SI (tons) & $61,72,213$ & $61,89,917$ \\
Installed capacity of gas based SI (tons/year) & $96,00,000$ & $96,00,000$ \\
Capacity utilization of gas based SI production & $64.29 \%$ & $64.47 \%$ \\
Production of coal based SI (tons) & $168,21,369$ & $170,65,432$ \\
Installed capacity of coal based SI (tons/year) & $238,14,000$ & $253,35,000$ \\
Capacity utilization of coal based SI production & $70.63 \%$ & $67.35 \%$ \\
Production of gas + coal based SI & $229,93,572$ & $232,55,349$ \\
Installed capacity of gas + coal based SI (tons/year) & $334,14,000$ & $349,35,000$ \\
Capacity utilization of gas + coal based SI production & $68.81 \%$ & $66.56 \%$ \\
\hline
\end{tabular}

production of SI dropped to 20.557 million tons in the year 2011-2012 owing to various interconnected reasons [8]. Since India is the world's largest producer of SI, concrete road map delineation for sustainable development demands that the literature be reviewed thoroughly.

\section{Evolution and Transformation of SI Industry}

Traditionally, steel scrap is the main feed to the electric arc furnace. However, steel industry is faced with the problems of less generation of scrap accompanied by greater demand. The SI industry came into existence all of a sudden, when mini steel plants were looking out for raw materials randomly. Since India has adequate coal deposits, their utilization for steel plants was considered to be of prime importance and production of coal based SI was considered as a viable option.

In India, the SI industry grew at a very slow speed till the mid of 1980s due to government's restrictive licensing policies. However, the de-licensing of DRI production in the year 1985 proved to be a historical event for the industry in general and for steel industry in particular. Since then the SI industry has witnessed enormous growth.

Between 1980 and 1988 there were only three plants with a very limited capacity. In the late eighties as a result of the discovery of natural gas, the domestic producers started setting up gas based SI plants. The first one was setup by Essar Steel Ltd. at Hazira Gujarat in 1990. India subsequently became the largest producer of SI in 2002 and continued to be so for subsequent years in succession [9].

During the eighties there was a remarkable demand for SI due to shortage of scrap and many SI plants were established after 1985. Thus, during the eighties quality of SI was not an important factor as compared to quantity. As there was a huge demand for SI due to the shortage of scrap, very little attention was paid to the quality of SI. However, during the nineties there was a good competition among the SI plants, and hence, there was a need to focus on the quality and productivity improvement to survive in the competition. The small size of the industrial units became a viable model which was nearer to either iron ore source or coal source [10]. Table 1 shows the production, installed capacity, capacity utilization of gas and coal based SI [11].

After the formation of Sponge Iron Manufacturers Association (i.e. SIMA) in the year 1992, the SI manufacturers had to set/establish standards of quality of SI and that is how quality of SI gradually became a point of concern.

\section{Present Scenario of SI Industry}

Today steel industry is facing a situation of demand for scrap being greater than the supply. Therefore, SI is likely to continue to remain the major feed for electric arc furnaces. While huge investments are taking place in coalbased sector, the supply of the natural gas is limited. There has been continuous research going on in the design of blast furnaces along with a growing environmental awareness due to strict government regulation and control.

There is a great demand of SI at present and to cope with the demand, lot of mini and medium scale SI plants are coming up. There is a race among the SI manufacturers to produce a good quality SI at a lower cost. However, the systematic guidelines or mechanisms are not present that could be readily used for quality management in the SI industry.

It is reported that the SI industry in the mineral rich belts of the country has registered phenomenal growth, where mushrooming of growth had started most markedly after 2002 [12]. This growth can be attributed to a number of factors, such as relatively low cost of investment, ease of SI plant implementation, clear-cut technology of direct reduction, better quality end products, availability of mineral resources, availability of labour as well as professional technical expertise etc. The tremendous growth of SI industry over the world could be attributed to the advantages of using SI in electric arc furnaces, thus partly substituting the scrap. 
SI Industry: Quality Related Aspects

The past literature has presented very strong evidence that the SI industry has addressed the quality related issues pertaining to the raw material and products. However, the enterprise wide application of quality related aspects has not received much attention. For example, it is reported that the quality of steel has improved dramatically in US due to technological advances and quality control [13]. On the other hand, Srajkumar [14] observed for Indian steel industry that productivity improvement is possible through usage of state-of-the-art technology, higher quality raw materials, higher level of efficiency of operations, effective management practices and higher level of motivation amongst employees. However, such initiatives are not visible in most of the plants in India. Since, the coal based DRI plants often experience problems with respect to formation of accretion resulting in reduced production rate and shorter campaign life, fluctuation in product quality, high coal consumption, etc., the chemical aspects related quality initiatives in the SI industry have received even greater attention. Furthermore, the problem is compounded with deteriorating quality of coal and iron ore particularly for manufacturers compelling them to use multiple sources of raw materials with deteriorating and varying quality. Thus, the operator is often required to manipulate a large number of parameters to maintain a stable process condition, which is a very difficult task [15]. To look for other alternatives to coal is a distant possibility for the industry, since India does not have ample reserves of natural gas [16]. Coal, on the other hand, is abundant and lower grade coals can be used without difficulty. In terms of capital cost, a coal based SI unit is generally small in capacity and can be installed and operated with a much smaller investment. Moreover, this cost advantage of the SI industry is also responsible for lack of innovation in the quality management related initiatives, especially in India.

In absence of comprehensive studies for the SI industry of India, it is imperative that the published literature be used to draw inferences, so that more specific studies can be planned as well as executed for quality management and improvement. In view of this, there is a need to generate company specific data and it is suggested that the comparative assessments be made after critical statistical evaluation of the generated data for the purpose of quality management related decision making [17]. Long back, Rao [18] had expressed a necessity to plan for technological innovation to achieve production objectives in SI industry, and advocated a need for such technology to be developed in India, or imported and adapted to suit indigenous conditions.

For the purpose of quality management in the field of iron and steel making industry, Spengler [19] had proposed use of new concepts, especially for eco-management. Chan et al. [20] have reported a need to carry out energy audits in the iron and steel industry to get more in depth understanding of state-of-the-art quality management initiatives in these industries. In addition to this, Chen et al. [21] have suggested that technological leapfrogging could serve as an alternative pathway towards a more environmentally sustainable iron and steel industry. Dutta and Mukherjee [22] have reported the energy consumption projection scenario for 2001-2031 (based on the Modeling exercise for India). Moreover, the authors have further expressed a need to carry out more and more studies pertaining to the SI industry using the mathematical modeling approach. Furthermore, the use of modeling approach has shown commendable benefits in different types of industries. Hence, exploring these options will definitely ensure cost effectiveness and competitiveness of this key sector in the global market.

\section{Conclusions}

It is becoming increasingly clear and urgent that humanity must address quickly the rapid degradation in the quality of our planet's environment. All the growth-oriented sectors in a developing economy consume enormous energy in their production processes. Steel, aluminium and cement are the key manufacturing industries in India which provide inputs to various other sectors such as construction, transportation, power transmission, etc. As a result, their demand is consistently rising and will continue to rise in the future. These industries heavily rely on the energy and raw materials such as iron ore, coal, electricity, and fuel oil, whose dearth of supply can act as severe production constraints over a period of time and can hinder sustainable development. Hence, it becomes imperative for these industries to continuously innovate to develop more efficient techniques.

Traditionally, scrap has been the main feed to the electric arc furnace. However, with more and more continuous casting in use, the application of scrap has reduced drastically. Production of SI in India as an alternative feed material to steel melting scrap, which was being imported in large quantities by the electric arc furnaces and induction furnace units, has resulted in considerable savings in foreign exchange. In addition to that, today, the steel industry is growing at very high rate and at the same time availability of pre-reduced materials such as scrap is decreasing day by day. Thus SI is fast replacing the scrap. Presently, there are more than 500 SI manufacturing units in India. The number is growing every month. There is mushrooming of mini SI plant with capacity of 50 tons/day due to small investment of 5-6 crores. These plants are 
able to maintain the prices but not quality of the product. Besides, there is no process control as most of them go for coal based plant. The quality of product is always neglected for higher and higher production targets in the industry. This emphasizes the need of quality improvement along with productivity in the SI industry.

In view of the above, it is apparent that the improvement in productivity can be brought about by increasing the output or maintaining the current level of output and a reduction of inputs by minimizing wastage and optimum utilization of the resources. In addition to this, increasing the output without any change in the inputs by adopting new and improved working methods such as new technologies and technological innovations can help the industry. Furthermore, people working smarter, their regular training, continuing education and quality control are also very much needed. It is widely known in other industries that factors affecting competitiveness and innovation are human resources, trade issues, customers, investors, regulatory policies, $\mathrm{R} \& \mathrm{D}$, market focus, management's role, etc. However, presently there is no specific framework of quality management, which could identify the critical success factors for the Indian SI industry. Thus, it may be concluded that a clear and precise framework/ mathematical model is the need of the hour for achieving the desired quality in the Indian SI industry.

\section{References}

1. Overview of Iron \& Steel Industry, http://steel.gov.in/Annual\% 20Report $\% 20 \% 282001-02 \% 29 /$ Chapter\%20II.pdf. Accessed on 01 Nov 2012

2. Industry overview-Indian steel sector, http://indiasteelexpo.in/ IndustryOverview.php Accessed on 03 Nov 2012

3. S. Choudhury, Orisa: an emerging state in steel sector (2005), available at http://orissa.gov.in/e-magazine/Orissareview/may 2005/engpdf/orissa_an_emrging_state_in_steel_sector.pdf Accessed on 11 Sept 2012

4. J.M. Reddy, Role of raw materials for production of sponge iron. Steelworld Aug, 40-42 (2010)
5. L.G. Burange, S. Yamini, Competitiveness of the firm in Indian Iron and Steel Industry, Working Paper UDE33/2/2010, University of Mumbai, Department of Economics, Feb 2010

6. P.K. Misra, Report of the working group on steel industry for the twelfth five year plan (2012-17), Ministry of Steel (Nov. 2011), http://planningcommission.nic.in/aboutus/committee/wrkgrp12/ wg_steel2212.pdf Accessed on 03 Nov 2012

7. S. Sengupta, Indian steel: big challenge ahead. Steelworld April, 26-42 (2012)

8. Statistics from official website of Sponge Iron Manufacturers Association, www.spongeironindia.in/prodfig06-07.html Accessed on 04 Nov 2012

9. Sponge iron: a nerve for steelmaking http://www.steelworld.com/ a\%20nerve.htm Accessed on 05 Nov 2012

10. S.C. Khattoi, Sponge iron industry: past present future, DRI Update. J. Sponge Iron Manuf. Assoc. 10-13 (2011)

11. An official website of Sponge Iron Manufacturer's Association, www.spongeironindia.in. Accessed on 10 March 2012

12. P. Sen, Contribution of secondary steel sector in Indian iron and steel industry-A perspective study, DRI Update. J. Sponge Iron Manuf. Assoc. Jan, 28-30 (2011)

13. R.J. Fruchan, D.A. Cheij, D.M. Vislosky, Factors influencing innovation \& competitiveness in the steel industry, Working Paper 059, Sloan Steel Industry Study, Carnegie Mellon University (1997)

14. Srajkumar, Productivity Improvement in The Indian Steel Industry (2011), www.classle.net/projects/projects_ideas/productivityimprovement-indian-steel-industry. Accessed on 30 Sept 2011

15. DRI Update. J. Sponge Iron Manuf. Assoc. India Jan, 1 (2011)

16. R.S. Borwankar, Gas based sponge iron industry-Outlook, DRI Update. J. Sponge Iron Manuf. Assoc. Jan, 14-19 (2011)

17. J.C.M. Farla, K. Blok, The quality of energy intensity indicators for international comparison in the iron and steel industry. Energy Policy 29(7), 523-543 (2001)

18. T.R. Rao, Scenarios for the Indian iron and steel industry. Long Range Plan. 17(4), 91-101 (1984)

19. T. Spengler, J. Geldermann, S. Hähre, A. Sieverdingbeck, O. Rentz, Development of a multiple criteria based decision support system for environmental assessment of recycling measures in the iron and steel making industry. J. Clean. Prod. 6(1), 37-52 (1998)

20. D. Chan, L. Yih, K.H. Yang, J. Lee, G. Hong, The case study of furnace use and energy conservation in iron and steel industry. Energy 35(4), 1665-1670 (2010)

21. Y. Chen, U. Farinelli, T.B. Johansson, Technological leapfrogging: a strategic pathway to modernisation of the Chinese iron and steel industry? Energy Sustain. Dev. 8(2), 30-38 (2004)

22. M. Dutta, S. Mukherjee, An outlook into energy consumption in large scale industries in India: the cases of steel, aluminium and cement. Energy Policy 38(11), 7286-7298 (2010) 